CIVICS EDUCATION AND SOCIAL SCIENSE JOURNAL(CESSJ)

Volume 2 Nomor 1 Bulan Juni 2020

\title{
INTERNALISASI INDEOLOGI PENDIDIKAN MULTIKULTURAL DALAM MENUMBUHKAN KESADARAN PLURALISME DI UNIVERSITAS MUHAMAMDIYAH KUPANG
}

\author{
Syahrul \\ Fakultas Keguruan dan Ilmu Pendidikan, Universitas Muhammadiyah Kupang \\ e-mail: syahrulkadir7@gmail.com
}

\begin{abstract}
Abstrak
Tujuan penelitian ini adalah mengkaji ideologi pendidikan multikultural yang diterapkan dalam menumbuhkan kesadaran pluralisme di UMK. Metodepenelitian ini adalah kualitatif denganpenentuan subjekpurposive samplingyang terdiri darimahasiswa Islam, Protestan, Katolik, dan dosen. Data penelitian dikumpulkan melalui wawancara, observasi, dan catatan lapangan yang dianalisis dengan teknik lingkaranyang bergerak di antara pengumpulan data, pengorganisasian data, pembacaan, memoing, deskripsi, klasifikasi, penafsiran, dan penyajian/visualisasi.

Hasil penelitian menunjukkan bahwa internalisasi pendidikan multikultural di UMK dipengaruhi oleh tiga ideologi, di antaranya [1] multikulturalisme konservatif merupakan ideologi yang paling berpengaruh, oleh karena itu, ideologi ini menghambat proses penumbuhan kesadaran pluralisme di UMK.[2] Multikulturalisme liberal banyak disalah artikan di UMK karena pada prinsifnya ideologi ini adalah bagian dari pluralisme yang dianggap tidak sejalan dengan agama Islam. [3] Multikulturalisme kritis adalah sebuah terobosan baru dan juga paradigma baru di UMK yang sulit mucul di permukaan karena mengalami tekanan secara struktural.
\end{abstract}

Kata Kunci: IdeologiPendidikan Multikultural, Kesadaran Pluralisme

JORNAL PROGDI PPKn, FKIP UNIVET BANTARA SUKOHARJO BEKERJA SAMA DENGAN ASSOSIASI PROFESI PENDIDIKAN PANCASILA DAN KEWARGANEGARAAN (AP3KNI) JAWA TENGAH 
CIVICS EDUCATION AND SOCIAL SCIENSE JOURNAL(CESSJ)

Volume 2 Nomor 1 Bulan Juni 2020

\section{Abstract}

The study focused on the internalization of multicultural educational ideologies to raise consciousness of religious pluralism at UMK. The research uses qualitative method with purposive sampling to select subjects such as Islamic, Protestant, Catholic students, and lecturers. Collecting data by interviews, observations, and field notes which were analyzed into one circle amongdata collection, data categories, reading, memoing, description, classification, interpretation, and visualization. The study shows that internalization of multicultural education at UMK was influenced by three ideologies such as [1] multiculturalism conservative was very influential ideology, therefore, it obstructs process of the emphasizing pluralism consciousness at UMK. [2] Multiculturalism liberal has misconception at UMK because precisely it is part of pluralism that has not different way with Islam.[3] Multiculturalism critical is new innovation and paradigm at UMK which is difficult appearing because they are structurally oppressed.

Keywords:Ideology of Multicultural Education, Pluralism Consciousness

\section{PENDAHULUAN}

Di lembaga pendidikan Muhammadiyah, pluralisme dan multikulturalisme merupakan sunnatullah yang tidak bisa diingkari karena nilai-nilai penting bagipembangunan keimanan terdapat di dalam filsafat pluralisme dan multikulturalisme(Efendi, 2013). Oleh karena itu, Gorski memetakan tiga ideologi yang sangat berpengarush di dalam pendidikan multikultural di antaranyaideology pendidikan multikultural konservatif, liberal, dan kritis (Gorski, 2009).Ketiga ideologi ini memiliki karakteristi, yaitu [1] bersifat demokratis, setara danadil;[2]memiliki sifat humanis, damai, dan kebersamaan; dan [3]memiliki sifatpengakuan, penerimaan dan penghargaan keberagamanbudaya. Ideologi pendidikan multikultural memiliki perbedaan secara signifikian dengan ideologi yang lainnya karena menganut dan memiliki landasan epistemologi nilai-nilai pluralisme. Selain itu, pendidikan multikultural di lembaga pendidikan Muhammadiyah memegang teguh nilainilai yang didasarkan pada kewahyuan, sedangkan pendidikan multikultural yang bercirikan ideologi Barat memegang teguh nilai-nilai yang berdasarkan pada hak asasi manusia(Efendi, 2013).

Aspek yang mendorong pelaksanaan pendidikan multi kultural di Universitas Muhammadiyah Kupang (UMK) adalah pentingnya kesadaran pluralisme untuk menjaga eksistensi wargaMuhammadiyah agar tetap terwujud toleransi antara mahasiswa Islam, Katolik, dan Protestan, serta 
CIVICS EDUCATION AND SOCIAL SCIENSE JOURNAL(CESSJ)

Volume 2 Nomor 1 Bulan Juni 2020

terhindar dari prasangka negatif terhadap kelompok lain, misalnya rasisme, sukuisme, bias gender, dan pobia agama, serta harus memiliki sikap inklusif terhadap perbedaanagama, status sosial dan ekonomi, bahasa, dan budaya. Selain itu, memberikan kesempatan atau liburkepada mahasiswa non-Muslim untuk merayakan hari raya agama mereka serta meperkuat sikap mereka agar merasa menjadi bagian dalam pengambilan keputusan secara demokratis di UMK (Efendi \& Suswanta, 2017). Lembaga pendidikan Muhammadiyah adalah organisasi yang pluralis. Hal ini dapat kita lihat dalam sejarah pekembangannya karena Muhammadiyah sangat terbuka denganorganisasi non-keagamaan. Bahkan organisasi non-keagamaanseperti ISDV (Indische Social Demochratische Vereeniging) yang berhaluankomunis pun juga membangun hubungan baik dengan Muhammadiyah. Ini terbukti dengan adanya undangan Ahmad Dahlan kepada tokoh ISDVseperti Semaun, Darsono, dan Baars untuk mengikuti rapatterbuka Muhammadiyah yang berlangsung di Kauman. Dalam rapat tersebut, organisasi Muhammadiyah menunjukkan keinginanuntuk mengembangkan kultur dialog lintas agamadan etnis (Biyanto, 2013).

Saat ini,UMKberusaha untuk mengembangkan dan menumbuhkan kesadaran pluralisme melalui pendidikan multikultural. Semangatpluralisme ini tentu akan sangat berarti bagi mahasiswa non-Muslim yang jumlahnya $70 \%$ sedangkan mahasiswa Islam 30\%. Sehingga kesadaran pluralisme ini justru akan membantu mahasiswa yang beraga Islam karena dari segi jumlah mereka minoritas baik di likungan UMK maupun di lingkungan masyarakat Timor. Hal ini sejalan dengan temuan Biyanto bahwa ada beberapa sekolah Muhammadiyah di daerah mayoritas Kristen, seperti di Nusa Tenggara Timur, justru memilikibanyak murid beragama Kristen. Hal ini kemudian menimbulkanguyonan di kalangan warga persyarikatan bahwa ada banyak pastor alumni sekolah Muhammadiyah. Bahkan UMK yang semestinya singkatan dari "Universitas Muhammadiyah Kupang," dipelesetkan dengan "Universitas Muhammadiyah Kristen" karena memiliki 70\% mahasiswa yang beragama Kristen(Biyanto, 2013, pp. 330-331).

Hal di atas menunjukkan bahwa meskipun UMK berideologi Islamnamun tetap memiliki sikap inklusif terhadap agama lain yang ditunjukkan melaluisikap toleransi terhadap agama Kristen Protestan dan Khatolik di NTT serta agama lainnya. 
CIVICS EDUCATION AND SOCIAL SCIENSE JOURNAL(CESSJ)

Volume 2 Nomor 1 Bulan Juni 2020

Kesadaran pluralisme yang ditanamkan oleh tokoh-tokoh Muhammadiyah salah satunya adalah Ahmad Syafi Ma'arif yang menunjukkan komitmen untukmenghadirkan wajah Islam moderat dan ramah terhadapkeanekaragaman agama dan kultur(Syamsuddin, 2018). Selain itu, ikhtiar untuk menumbuhkan nilai-nilai pluralisme jugadilakukan melalui amal usaha di bidang pendidikan, yaitu melalui pendidikan multikultural. Oleh karena itu, pendidikan multikultural di lembaga pendidikan Muhammadiyah di Kota Kupang mulai dari tingkat SD, SMP, SMA, dan perguruan tinggi telah dimaksimalkan sebagai layanan publik untukmendidik anak-anak dari berbagai jenis agama, ras, dan suku(Tholkhah, 2013).Amal usaha Muhammadiyah di bidang pendidikan kian terasa di daerah-daerah yangberpenduduk minoritas Islam misalnya di NTT. Oleh karena itu,kita bisa menilai bahwa UMK telah memberikan layanan yang humanis kepada masyarakat yang non-Muslim di NTT.

Upaya UMK untuk menumbuhkan nilai-nilai pluralismedengan mengajak funding agencies asing memang sempat memunculkanrespon negatif dari kalangan internal dan eksternal Muhammadiyah. Mereka yang anti terhadap pluralisme menganggap bahwa pendidikan multikultural mengajak pada penerimaan semua agama, tetapibagi mereka yang pro terhadap pluralisme menganggap bahwa itu adalah keputusan yang salah kaprah karena bagi mereka, keberagaman memang diakui eksistensi dalam al-Qur'an, tetapi penerimaan tersebut tidak sama dengan membenarkan dan meyakini. Ketidak setujuan tersebut kemudian mereka ekspresikan dengan sikap perlawanan, misalnya mereka berkonsolidasi untuk mematahkannya melalui khutbah Jum'at, ceramah, kultum, dan forum-forum kajaian keislaman. Mereka kerap meluncurkan kritik pedas terhadap warga Muhammadiyah yang mendukung pluralisme tersebut. Bahkan mereka telah memvonis bahwa warga Muhammadiyah pro multikulturalisme dan pluralisme bukan bagian dari organisasi Muhammadiyah (Efendi \& Suswanta, 2017; Syamsuddin, 2018).

Namun berbagai kritik tersebut di atas tidak mengurangi keinginan dosen UMK yang pro terhadap pluralisme untuk tetap menerapkan pendidikan multikultural di kelas-kelas perkuliahan, lingkungan kampus, dan kehidupan bermasyarakat di Kota Kupang. Bahkan UMK semakin menggalakkan ambisinya dengan menerima sebanyak mungkin mahasiswa non-Muslim untuk bergabung bersama-sama di dalam kampus UMK demi terwujudnya Muhammadiyah yang moderat dan berkemajuan. Lebih jauh lagi, mereka 
CIVICS EDUCATION AND SOCIAL SCIENSE JOURNAL(CESSJ)

Volume 2 Nomor 1 Bulan Juni 2020

menunjukkan bahwaUMK ingin menjadi lembaga pendidikan yang mengakui keberagaman yang ada pada masyarakat NTTdengan cara menumbuhkan nilainilaipluralisme di lingkungan kampus dan masyarakat(Biyanto, 2013; Efendi \& Suswanta, 2017; Syamsuddin, 2018). Selain itu, hal tersebut bukanlah yang pertama kali di Muhammadiyah karena sebelumnya terdapat beberapa penelitiyang menunjukkan bahwa Muhammadiyah adalah organisasi yang inklusif seperti yang pernah dibuktikan oleh Nakamura, James L. Peacock, Ahmad Jainuri, dan Alwi Shihab. Mereka melihatbahwa meskipun Muhammadiyah sangat menekankan pengamalan Islam Tauhid, tetapipada umumnya para tokoh Muhammadiyah telah menanamkan nilai-nilai pluralisme dengan cara bersikap inklusif terhadap budaya masyarakat dan kelompok agama lainnya (Biyanto, 2013; Efendi, 2013; Syamsuddin, 2018).

Oleh karena itu, UMK menumbuhkan pluralismedengan cara menginternalisasikan ideologi-ideologi pendidikan multikultural melalui bebagai pendekatan di dalam proses pembelajaran. Selain itu, internalisasi ini ditujukan kepada mahasiswa non-Muslim agar stigma negatif tentang Islam bisa diluruskan. Misalnya, stigma yangmelekat tentang Islam sebagai teroris (islamophobia), aliran-aliran radikal dalam Islam dan sebagainya. Secara umum, pendidikan multikultural diterapkan dengan harapan agar semua mahasiswamengenal ideologi dan budayanya masing-masing dengan baik, sehingga setelah mendapatkan pemahaman tentang pluralisme maka timbul sikap inklusif antara mahasiswa non-Muslim dan Islam.

\section{KAJIAN PUSTAKA}

\section{Konsep Multikulturalisme dan Pluralisme}

Secara sederhana, 'multikultural' dapat berarti 'keragaman budaya'. "Istilah multikultural dibentuk dari kata 'multi' yang berarti plural; banyak; atau beragam, dan 'kultur' yang berarti budaya”(Abdullah, 2005 , p. 13). Konsep "multikultural" pada umumnyadipahami sebagai sebuah keberagaman budaya di dalam masyarakat,sedangkan pluralisme tidak hanya bermakna penerimaan dan pengakuan kemajemukan, tetapi pengakuan dan penerimaanindividu yang didasarkan secara politis, sosial dan ekonomi. Oleh karena itu, pendidikan multikultural adalah proses internalisasi nilai-nilai kebudayaan secara humaniskepada peserta didik yang didasarkan pada esensi pluralisme sebagai pembelajaran dan penerimaankeberagaman budaya, agama, bahasa, ras, status sosial dan 
CIVICS EDUCATION AND SOCIAL SCIENSE JOURNAL(CESSJ)

Volume 2 Nomor 1 Bulan Juni 2020

ekonomi. Dalam konteks ini, pendidikan multikural memiliki limaprinsif utama di dalam proses pembelajaran, yaitudemokrasi, pluralisme, inklusif, kebebasan dan persamaan (Efendi, 2013).

Selain itu, pluralisme dapat juga dimaknai sebagai keberagaman di dalam ideologi-ideologi itu sendiri. Karena di dunia ini kita akan menemui banyak ideologi yang tidak hanya bersumber dari agama, tetapi ada juga dari lingkungan pendidikan dan tradisi masyarakat. Pluralisme juga tumbuh karena adanyaperbedaan-perbedaan manusia yang hidup di muka bumi yang memiliki keragaman agama, tradisi, budaya, pengetahuan, polapikir, hobi, minat dan potensi.Namun kerena keberagaman inilah, pluralisme sering disalah artikan seperti dianggap ajaran sesat. Selain itu, pluralisme juga selalu dianggap sama dengan toleransi(Efendi, 2013).Perlu dipahami bahwa pluralisme dan toleransi adalah dua konsep yang berbeda meskipun keduanya memiliki keterkaitan.

Tolerance respects the values of other people, whereas pluralism promotes its own value. Multiculturalism is influenced by pluralism and multiculturalism is ant pluralistic. Pluralism and multiculturalism are not contrary concepts because multiculturalism can be understood as the existence of various cultures and thus it is just configuration of pluralism(Josefová, 2014, p. 1020).

Dari uraian tersebut dapat dimaknai bahwa pada prinsipnya toleransi hanya bermakna sebuh respon kita terhadap orang lain yang berbeda dengan kita, sedangkan pluralisme adalah pengakuan dan penerimaan terhadap perbedaan budaya, bahasa, ras, agama, satus sosial dan ekonomi dan lainnya. Meskipun kita menerima dan mengakui, itu tidak berarti kita meyakina ideologi lain dan menjadi seperti mereka dalam hal budaya, ras, etnis dan bahasa.

Pemahaman danpemaknaan terhadap pluralisme sesungguhnya memiliki makna yang cukupsignifikan dalam kehidupan yang kompleks dan heterogen. Namun istilahpluralisme sendiri telah menjadi komoditas yang masuk dalam ranah otoritaskeberagamaan. Fatwa MUI bahwa pluralisme merupakan paham yang sesat danmenyesatkan merupakanbukti bahwa kata pluralisme memang memiliki sensitivitas. Namun secara esensial,pluralisme sesungguhnya memiliki tujuan yang mulia dalam menciptakankehidupan yang toleran dan saling menghargai antara umant beragama (Efendi, 2013). Sementara itu, multikulturalisme tidak terlepas 
CIVICS EDUCATION AND SOCIAL SCIENSE JOURNAL(CESSJ)

Volume 2 Nomor 1 Bulan Juni 2020

daripengaruh filsafat post-modernisme, yang berangkat dari pemikiran tentang ketidakpercayaan terhadap segala bentuk narasi besar dan penolakan terhadap segala bentuk pemikiran yang menyeluruh. Multikulturalisme juga menghaluskan sensitifitas manusiaterhadap perbedaan dan memperkuat kemampuan toleransi terhadap realitas yangterukur. Multikulturalisme menolak kebenaran tunggal atau yang bersifat absolutdan menghindari sikap klaim kebenaran. Oleh karena itu, pluralisme dan multikulturalismemenganggap bahwa kenyataan adanya masyarakat plural itu menjadi suatu fakta yang tidak bisa disangkal. Sehingga hal ini harus diperkuat dengan membangun prinsip kesadaran pluralisme dan multikulturalisme, yakni paham yang mengakui adanya keragaman dalam kehidupan sekaligus memperlakukan orang lain secara sama dan proporsional(Efendi, 2013).

\section{Indeologi Pendidikan Multikultural}

Ideologi pendidikan multikultural menurut Gorki terdiri atas tiga, yaitu multikulturalisme konservatif, multikulturalisme liberal, dan multikulturalisme kritis (Gorski, 2009).

[1] Multikulturalisme konservatif adalah sebuah pembelajaran yang menggunkan pendekatan perbedaan dan asimilasi kebudayaan. "Conservative multiculturalists see themselves as committedto equality, but apply that commitment only to those willing toadopt mainstream culture and its attending values, mores, andnorms" (Gorski, 2009, p. 311). Multikulturalisme konservatif terfokus pada sebuah defisit ideologi, oleh karena itu, kesetaraan dapat terbentuk melalui mobilitas sosial yang dipasilitasi hanya ketika berlangsungnya sebuah proses pembelajaran. Ideologi ini juga ditujuakan kepada guru sebagai persiapan untuk menghadapi perbedaan di dalam sistem pendidikan (Gorski, 2009).

[2] Multikulturalisme liberal menggunakan pendekatan kemanusiaan, pluralisme, penerimaan dan penghargaan terhadap perbedaan, dan juga mendukung program-program yang memperkuat dan mengapresiasi perbedaan, selain itu mengabaikan sebuah cara-cara yang anti terhadap perbedaan. Ideologi ini menggunakan dua pendekatan, yaitu pembelajaran dengan sensitivitas budaya dan toleransi (hubungan kemanusian, hubungan didalam kelompok, 
CIVICS EDUCATION AND SOCIAL SCIENSE JOURNAL(CESSJ)

Volume 2 Nomor 1 Bulan Juni 2020

pendidikan toleransi, dan penghargaan perbedaan), dan pembelajaran dengan kompetensi multikultural (pembelajaran responsif). Ideologi ini ditujukan kepada guru untuk menghadapi adanya bias dan prasangka di dalam pembelajaran (Banks, 2017; Gorski, 2009).

[3] Multikulturalisme kritis adalah cenderung pada sebuah pertanyaan yang sifatnya esensial dan lebih mendalam pada eksistensi manusia itu sendiri. Multikulturalisme kritis juga mengedepankan pada konstruksi pendidikan misalnya politik dan struktur pendidikan. Ideologi ini menggunakan pendekatan pembelajaran konteks sosial politik dan pembelajaran anti hegemoni (kritik teori, pendidikan pembebasan, dan pedagogi kritis). Ideologi ini mempersiapkan guru untuk dapat melakukan aktivitas sosial seperti mengkritik struktur dan sistem pendidikan yang sangat mendominasi dan mengekang (Banks, 2017; Gorski, 2009).

\section{METODE}

Jenis penelitian ini adalah penelitian kualitatif yang didasarkan pada metode verstehenuntuk menafsir kenyataan sosial di UMK yang terdiri darilingkungan kampus, proses perkuliahan, kurikulum, hubungan sosial antara mahasiswa dengan dosen, mahasiswa dengan mahasiswa, dan dosen dengan dosen (Berger \& Luchmann, 2019).Pemilihan subjek penelitian ini dengan purposive sampling yang terdiri dari mahasiswa Islam, Kristen Protestan dan Katolik, dan dosen. Proses pengumpulan data dilakukan dengan [1] mengobservasilingkungan kampus untuk mencari tahu bagaimana internalisasi ideologi pendidikanmultikultural di UMK;[2]mewawancarai mahasiswa untuk mencari tahu pemahaman mereka tentang pluralisme, serta mewawancarai dosen untuk mencari tahu bagaimana menginternalisasikan ideologi pendidikan multicultural; dan [3] mencatat pengalaman-penglaman unik di dalam proses pembelajaran serta lingkungan kampus UMK. Alur analisis data bergerak dalam lingkaran analisis, yaitu peneliti bersinggungan dengan beberapa saluran analisis yang berputar dan terus berputar di antaranya mengorganisasikan data, pembacaan, memoing, deskripsi, klasifikasi, penafsiran, dan penyajian/visualisasi(Creswell, 2013). 
CIVICS EDUCATION AND SOCIAL SCIENSE JOURNAL(CESSJ)

Volume 2 Nomor 1 Bulan Juni 2020

\section{HASIL PENELITIAN DAN PEMBAHASAN}

\section{Ideologi-Indeologi Pembentuk Kesadaran Pluralisme di Universitas Muhammadiyah Kupang}

Idiologi sudah menjadi hak asasi manusia sehingga setia orang memiliki kebebasan untuk memilih sesui dengan seleranya. Begitu pun juga dalam lingkungan pendidikan, setiap orang harus memiliki idiologi sebagai landasan hidup dan berpikir. Oleh karena itu, dalam menanamkan kesadaran pluralisme di UMK dipengaruhioleh tiga jenis ideologi pendidikan multikultural, yaitu konservatisme, liberalisme, dan kritis:(Gorski, 2009)

\section{Tabel 1. Ideologi-ideologi Pendidikan Multikultural di UMK}

\begin{tabular}{|c|c|c|}
\hline $\begin{array}{l}\text { Ideologi } \\
\text { Pendidikan } \\
\text { Multikultural }\end{array}$ & Pendekatan Pendidikan & \\
\hline Konservatif & Teaching the "Other" & 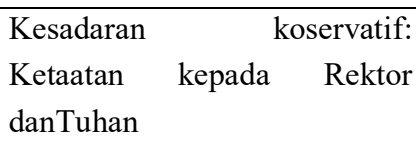 \\
\hline Liberal & $\begin{array}{l}\text { 1. Pembelajaran dengan pendekatan budaya } \\
\text { 2. Pembelajaran dengan pendekatan humanis }\end{array}$ & $\begin{array}{l}\text { Kesadaran liberal: Bebas dari } \\
\text { kekerasan simbolik dan } \\
\text { ketertindasan dalam lembaga } \\
\text { pendidikan }\end{array}$ \\
\hline Kritis & $\begin{array}{l}\text { 1. Pembelajaran dalam Konteks Sosiopolitik } \\
\text { 2. Pembelajaran sebagai Perlawanan dan Anti } \\
\text { Hegemoni }\end{array}$ & $\begin{array}{lr}\text { Kesadaran kritis: } & \text { Proaktif } \\
\text { dalam berbagai } & \text { bentuk } \\
\text { kebijakan pendidikan } & \end{array}$ \\
\hline
\end{tabular}

\section{a. Pendidikan Multikultural Konservatif}

Struktur pendidikan UMK yang sentralistik dipengaruhi oleh banyaknya dosen konservatif. Ini bisa dilihat dari bentuk-bentuk kebijakan yang semuanya berpusat pada Rektor dan juga menyerahkan nasib institusi kepada kehendak Tuhan. Oleh karena itu, multikulturalisme di UMK adalah didominasi oleh multikulturalisme konservatif. Mereka beranggapan bahwa bukan pluralisme ala Barat yang diinginkan di UMK akan tetapi pluralisme yang tidak hanya sekedar pengakuan keberagaman karena pluralisme merupakan sunnatullah. Konsep pluralisme yang mereka maksudkan dalam pendidikan multikultural inibukan yang bersifat sekularis, liberalistik, dan antroposentris seperti Barat, akantetapi 
CIVICS EDUCATION AND SOCIAL SCIENSE JOURNAL(CESSJ)

Volume 2 Nomor 1 Bulan Juni 2020

pluralisme yang mereka maksudkan adalah pluralisme yang memadukan antarakepentingan individu dan sosial, antara nilai-nilai yang berasal dari Tuhan danaturan-aturan yang berasal dari pimpinan dalam hal ini Islam menyebutnya dengansyura bukan pluralisme(Biyanto, 2013).Hal ini dimaksudkan agar dominasi agama Kristen Protestan dan Katolik di UMK dapat dimusyawarahkan untuk merumuskan suatuperkara yang menghasilkan kerukunan antara mahasiswa Kristen Protestan, Katolik dan Islam di UMK. Lebih jauh lagi, musyawarah ini diharapkan tidak akan terjadi pertentangan dalamsatu kelompok dengan kelompok yang lain yang kemudian hari akanmenyebabkan timbulnya narasi-narasi yang saling memojokkan antara agama yang satu dengan agama yang lainnya.

Selain itu, konsep persamaan dalam pendidikan multikultural konservatif di UMKtidak seperti di Barat karena hanya mengakui persamaan hukum dimana merekadianggap sama dan harus setara di mata hukum. Akan tetapi persamaan yang diinginkan di UMKadalah semua orang harus diperlakukan sama dalam segala hal, karenamereka memang sama, jadi yang membedakan manusia adalah hal-hal yang bersifat kualitatif, moralitas, spiritualitas dan amalperbuatannya seperti keimanan, ketaqwaan, ketinggian akhlaknya kepada Tuhan. Sehinggatimbul konsep yang menuntut penghapusan hukum dan hak-hak istimewa yangtidak dibenarkan di UMK, yaitu paham yang menganggap bahwa persamaan kesempatan dalam pendidikanmerupakan prioritas utama karena pendidikan dapat menciptakan mobilitassosial yang mana semakin tinggi pendidikan seseorang maka semakin tinggi juga prestise, kemampuan dan kekayaannya.

Sebaliknya, mereka yang beraliran konservatif mengkritik konsep kebebasan Barat di UMK karena bagi mereka membiarkan segala yang diinginkan oleh manusia dalam mencapai tujuanhidupnya berupa kebahagiaan yang setinggi-tingginya adalah sebuah kekeliruan dalam Islam. Oleh karena itu, kebebasan demikian ditolak oleh kelompok konservatif diUMK, karena menurut mereka kebebasan yang dimaksudkandi UMK adalahsebuah kebebasan yang bertanggung jawab dan kebebasan yang dikendalikan olehkebebasan Pimpinan dan Tuhan. Lebih jauh lagi, konsep pluralisme yang mendatangkankeberkahan dan nilai tambah bagi kaum konservatif di UMK adalah hal yang 
CIVICS EDUCATION AND SOCIAL SCIENSE JOURNAL(CESSJ)

Volume 2 Nomor 1 Bulan Juni 2020

didasarkanpada perilaku ketaatan kepada Tuhan dan menghormati pimpinan.

\section{b. Pendidikan Multikultural Liberal}

Aliran multikultural liberal adalah mereka yang dikenal mewakili wacana keislaman yang bebas dan kontekstual. Kebanyakan dari mereka adalah dosen-dosen mudah di UMK yang banyak melahap wacana-wacana filsafat, karena pada umumnya merekalah yang memuculkan wajah baru UMK yaitu pluralisme.Misalnya, ilmu filsafat pendidikan dari Paulo Freire yang telah mereka terapkan, yaitu metode pembelajaran dialogis, membuat banyak mahasiswa lebih tertarik untuk mengikuti kuliah-kuliah mereka. Namun, secara kuantitatif jumlah mereka sangat kecil dibandingkan yang beraliran konservatif. Mereka selalu mendapat stigmatisasi dan penghakiman sepihak, seperti dituduh kafir, murtad, dan lain sebagainya. Meskipun memiliki pandangan liberal, tidak sedikit dari mereka yang memilih bungkam ketimbang mempublikasikan hasil-hasil pemikirannya yang beresiko mendapat kecaman dan labelisasi kafir dari mereka yang beraliran konservatif.

UMK yang memiliki ideologi terbuka terhadap semuah agama memudahkan untuk menumbuhkan kesadaran liberal pada setiap mahasiswa. Hal ini sejalan dengan hasil penelitian yangdilakukan oleh Puslitbang KehidupanKeagamaan badan Litbang dan DiklatKementerian Agama pada tahun 2011yangmenyatakan bahwa semakin tinggipemahaman keagamaan seseorangternyata makin berkurang pulaeksklusifisme beragamanya, dansebaliknya makin kurang pemahamankeagamaan seseorang maka makineksklusif orang tersebut(Saleh \& Doni, 2018). Oleh karena itu, menumbuhkan ideologi liberaldi UMK dapat di lakukan melalaui mata kuliah Pendidikan Multikultural. Perkulihan ini lebih tepatnya menggunakan pendekatan kebudayaan atau pendekatan humanis. Karena pada mata kuliah ini lebih banyak menggunakan teori-teori sosiologi yang sifatnya lebih rasional. Berbanding terbalik dengan mata kuliah AIK dan Bahasa Arab yang lebih cenderung Islamis, sehingga menyulitkanuntuk menumbuhkan kesadaran pluralisme pada mahasiswa Islam, Kristen Protestan dan Katolik. Meskipun banyak mahasiswa non-Muslim yang mengeluhkan mata kuliah AIK dan Bahasa Arab, mata kuliah ini masih tetap diwajibkan bagi 
CIVICS EDUCATION AND SOCIAL SCIENSE JOURNAL(CESSJ)

Volume 2 Nomor 1 Bulan Juni 2020

mereka. Oleh kaena itu, salah satu cara untuk memanimalisir masalah ini adalah secara perlahan di dalam mata kuliah pendidikan multikultural di masukkan materi yang membahas tantang pluralismeagama. Sehingga upaya untuk membebaskan mahasiswa non-Muslim dari mata kuliah AIK dan Bahasa Arab akan segera terlaksana.

\section{c. Pendidikan Multikutlural Kritis}

Aliran kritis ini sering juga dilabeli Muhammadiyah kiri(Syamsuddin, 2018). Mereka adalah para aktivis Muhammadiyah yang sangat kritis melihat persoalan ketimpangan sosial di lingkungan UMK. Mereka sering menjalankan peran oposisi terhadap status quo di UMK, dan selalu mengkritik kebiajakan-kebijakan pimpinan yang dianggap menyimpang serta tidak pro terhadap kemajuan institusi dan kesejahteraan dosen. Sasaran kritik mereka adalah orang-orang yang bekerja di UMK yang di saat bersamaan menjadi struktural dan birokrat di internal UMK atau di tempat lain. Mereka juga tidak setuju dengan dosen-dosen yang melakukan pungutan-pungutan liar misalnya jual buku dan modul serta kegiatan-kegiatan eksternal yang melakukan pungutan biaya kepada mahasiswa.Ini bisa dilihat dari keluhan mahasiswa.

Berdasarkan pengalaman saya, masih ada penindasan-penindasan kecil-kecilan yang dilakukan dosen terhadapa kami, karena ada dosen yang jarang masuk mengajar tetapi hanya datang saja menjual modulmodul kepada kami dengan harga yang tinggi, ada juga dosen yang masuk hanya menjelaskan beberapa materi lalu menyuruh mahasiswa untuk mengkaji dan mencari tahu sendiri. Ada dosen yang masuk hanya sibuk dengan dirinya sendiri setelah menyuruh mahasiswa berdiskusi. Ada dosen yang tidak memberikan kesempatan kepada mahasiswa untuk bertanya dan mengemukakan pendapatnya. Setelah itu, dosen memberikan pertanyaan kepada kami, tetapi saya juga tidak berani untuk menjawab dan tidak berani untuk mengemukakan sebuah pendapat(M. Bisik, personal communication, August 5, 2019).

Dosen-dosen yang termasuk dalam kategori di atas adalah mereka yang berlairan konservatif. Sehingga, dengan alasan ini, mereka sering menjadi sasaran kritis. Selain itu, mereka yang beraliran kritis juga sering mengkritik dosen abangan atau Muhammadiyah abangan, yaitu dosen yang dulunya bukan dari warga atau organisasi Muhammadiyah tetapi 
CIVICS EDUCATION AND SOCIAL SCIENSE JOURNAL(CESSJ)

Volume 2 Nomor 1 Bulan Juni 2020

karena kebutuhan karir, uang dan jabatan mereka bekerja di UMK. Dosen abangan di UMK kebanyakan berasal dari organisasi Islam yang pada umumnya sangat konservatif. Selain itu, dosen abangan di UMK banyak juga berasal dari organisasi HMI dan lain-lainnya.

\section{Internalisasi Pendidikan Multikultural di Universitas Muhammadiyah Kupang}

Internalisasi pendidikanmultikultural di UMKmemberi pelajaran dan menumbuhkan kesadaran pluralisme kepada mahasiswa untuk memiliki apresiasi dan respect terhadapbudaya dan agama di NTT. Atasdasar ini, penerapan pendidikan multikultural menekankan pada penumbuhan kesadaran pluralisme pada setiap mahasiswa yang didasarkan pada masing-masing budaya lokal untuksaling mengakui dan menghormatikeanekaragaman budaya dan agama yangdibalut semangat kerukunan danperdamaian di lingkungan kampus UMK. Oleh karena itu, terdapat satu titik temu yang menggambarkan bahwa dalam rangka mengintarnalisasikan nilai-nilai pendidikan multikultural di UMK menggunakan beberapa pendekatan, di antaranya: Pertama, ketebukaan (openness) memiliki makna bahwa meskipun Muhammadiyah beridentitaskan Islam, namun bukanberarti menutupdiri terhadap apa saja yang tidakIslam. Misalnya, UMK memberikan kebijakan kepada mahasiswa non Muslim untuk ikut mengenyam pendidikan dengan dengan cara tidak membeda-bedakan dengan mahasiswa yang Bergama Islam, baik itu dalam proses pembelajaran dan layanan administrasi. Penerimaan ini adalah sebagailangkah awal UMK untukmenanamkan nilai-nilai pendidikanmultikultural untuk mewujudkan kampus yang pluralis(Saleh \& Doni, 2018).

Kedua,toleransi (tolerance) ini dimaknai sebagai sikap saling menghargai, saling menghormati dan tidak semena-mena terhadap mereka yang minoritas. Misalnya toleran terhadap cara berpakaian para mahasiswa non Muslim, dan dalam saat yang bersamaan juga menuntut para mahasiswa non Muslim untuk bisa menyesuaikan dengan apa yang menjadi norma-norma berpakaian dalam lembaga pendidikan Muhammadiyah. Ketiga,unity indiversityadalah tidak berarti mengharuskanmahasiswa Islam membagikeyakinannya dengan keyakinanagama non Muslim di UMK. Sebaliknya,ini tidak berarti bahwa 
CIVICS EDUCATION AND SOCIAL SCIENSE JOURNAL(CESSJ)

Volume 2 Nomor 1 Bulan Juni 2020

mahasiswa non Muslim harus membagi keimanannyadengan mahasiswa Islam,tetapi mahasiswa yang Islam tetapmenjaga orisinalitas keislamannyabegitu juga dengan mahasiswa yang beragama Protestan dan Khatolik juga menjagakeyakinannya masing-masing(Saleh \& Doni, 2018).

\section{SIMPULAN}

Internalisasi ideologi pendidikan multikultural di UMK dalam rangka menumbuhkan kesadaranpluralisme cenderung didominasi oleh aliran konservatif. Oleh karena itu, internalisasi pendidikan multikultural berlangsung alot karena dosen yang konservatif tersebut anti terhadap pluralisme, dan masih adanya dosenyang belum memahami secara esensial konsep pendidikan multikultural baik secara teoritis maupunpraktis. Pada umumnya banyak dosen yang menganggap bahwa pluralisme sama dengan toleransi karena mereka mengaggap bahwa menerima banyak mahasiswa yang beragama Kristen Protestan dan Khatolik kuliah di UMK adalah sikap toleransi mereka terhadap agama lain. Ini menunjukkan bahwa ideologipluralisme di UMK belum dipahami dan diterima spenuhnya, justru masih terdapat unsur hegemoni kepada mereka yang non-Muslim karena mereka menganggap bahwa mewajibkan mata kuliah AIK dan Bahasa Arab pada mahasiswa non-Muslim adalah bagian dari pluralisme.

\section{DAFTAR PUSTAKA}

Abdullah. (2005). Pendidikan Agama Era Multikultural Multi Religius. PSAP Muhammadiyah.

Banks, J. A. (2017). An Introduction to Multicultural Education. Pearson Education.

https://www.pearsonhighered.com/assets/preface/0/1/3/4/0134800362.pdf

Berger, P. L., \& Luchmann. (2019). Tafsir Sosial Atas Kenyataan: Risalah Tentang Sosiologi Pengetahuan. LP3ES.

Bisik, M. (2019, August 5). Penerepan Pendidikan Multikultural (Syahrul, Interviewer) [Personal communication]. 
CIVICS EDUCATION AND SOCIAL SCIENSE JOURNAL(CESSJ)

Volume 2 Nomor 1 Bulan Juni 2020

Biyanto, B. (2013). Pengalaman Muhammadiyah Membumikan Nilai-nilai Pluralisme. ISLAMICA: Jurnal Studi Keislaman, 7(2), 318-339. https://doi.org/10.15642/islamica.2013.7.2.318-339

Creswell, J. W. (2013). Qualitative Inquiry and Research Design. SAGE Publication.

https://books.google.co.id/books?id=Ykruxor10cYC\&printsec=frontcover $\# \mathrm{v}=$ onepage \& $\mathrm{q} \& \mathrm{f}=$ false

Efendi, N. (2013). Pengembangan Pendidikan Islam Plural-Multikultural. Ta'allum: Jurnal Pendidikan Islam, 1(1), 13-28. https://doi.org/10.21274/taalum.2013.1.1.13-28

Efendi, \& Suswanta. (2017). Politics of Education: Multiculturalism Practice in Universitas Muhammadiyah Kupang, NTT. Iseedu, 1(1), 47-72. https://doi.org/10.23917/iseedu.v1i1.5420

Gorski, P. C. (2009). What we're teaching teachers: An analysis of multicultural teacher education coursework syllabi. Teaching and Teacher Education, 25(2), 309-318. https://doi.org/10.1016/j.tate.2008.07.008

Josefová, A. (2014). The Cultural Diversity as a Phenomenon of the Multicultural Society. Procedia - Social and Behavioral Sciences, 152, 1019-1021. https://doi.org/10.1016/j.sbspro.2014.09.266

Saleh, S. R., \& Doni, C. P. (2018). Penanaman dan Implementasi Nilai Pendidikan Multikultural (Studi Kasus di Universitas Muhammadiyah Gorontalo). Education Journal: Journal Educational Research and Development, 2(1), 41-58. repository.ikipjember.ac.id

Syamsuddin, M. (2018). Gerakan Muhammadiyah dalam Membumikan Wacana Multikulturalisme: Sebuah Landasan Normatif-Institusional. Jurnal Pemberdayaan Masyarakat: Media Pemikiran dan Dakwah Pembangunan, 1(2), 361. https://doi.org/10.14421/jpm.2017.012-08

Tholkhah, I. (2013). Pendidikan Toleransi Keagamaan: Studi Kasus SMA Muhammadiyah Kupang Nusa Tenggara Timur. EDUKASI: Jurnal Penelitian Pendidikan Agama Dan Keagamaan, 11(2).

JORNAL PROGDI PPKn, FKIP UNIVET BANTARA SUKOHARJO BEKERJA SAMA DENGAN 